\title{
Spatial characteristics of selective attention in letter matching
}

\author{
JAMES M. SKELTON and CHARLES W. ERIKSEN \\ University of Illinois, Champaign, Illinois 61820
}

\begin{abstract}
Circular arrangements of eight letters around a central fixation point were tachistoscopically presented. Two bar indicators appeared either simultaneously with or $80 \mathrm{msec}$ before the letters, designating a pair of letters at any of four spatial separations for a same/different judgment. The subject indicated with a lever movement whether the members of the pairs were same or different. The principal concern was the effect of physical separation between target letters when all letters appeared on foveal locations of equal acuity. Reaction time (RT) varied nonmonotonically with spatial separation, with adjacent and diametrically opposite pairs being fastest. Leading indicators produced faster responses than simultaneous indicators. "Same" judgments were faster than "different" judgments. Effects of interhemispheric or intrahemispheric presentation and orientation were such that they could not account for the spacing effect, nor could peripheral effects such as masking.
\end{abstract}

Experimental psychologists have long speculated that the locus of visual attention need not correspond to fixation. It was held that attention could be directed to any portion of a blank visual field in advance of the tachistoscopic exposure (Helmholtz, cited in James, 1890; Wirth, cited in Geissler, 1909) and that the focus of attention could be made to wander about the afterimage which lingered briefly following a tachistoscopic exposure (Wundt, 1900).

Experiments by Eriksen and his associates have shown that subjects can voluntarily alter the spatial distribution of visual selective attention when given a positional cue a fraction of a second before onset of a letter display. A series of experiments used a similar paradigm: A circular array of letters was presented, so that all letters were on loci of nearly equal acuity; enough letters were presented to overload subjects' short-term memory; and a partial report technique was used, with one or more indicators (e.g., black bars) which designated one or two letters. The attentional facilitation allowed by leading indicators was shown to be independent of eye movements (Eriksen \& Rohrbaugh, 1970; Eriksen \& Colegate, 1971; Colegate, Hoffman, \& Eriksen, 1973). The visual attentional field was found to have a minimum size, so that response-competitive letters within about $1 \mathrm{deg}$ of visual angle of a target letter greatly elevated reaction time (RT) to a greater extent than could be accounted for by masking or contour interference (Eriksen \& Hoffman, 1972a, b). The interference due

This research was supported by Public Health Service Research Grant MH-1206 and United States Public Health Service Research Career Program Award K6-MH-22014 to the second author. The paper is based on a thesis submitted by the first author to the University of Illinois in partial fulfillment of the requirements for his master's degree. Requests for reprints should be made to Professor Charles W. Eriksen, Psychology Building, University of Illinois, Champaign, Illinois 61820 . to response-competitive noise letters flanking the target letter did not disappear no matter how far in advance of target onset its position was indicated (Eriksen \& Hoffman, 1973; Eriksen \& Eriksen, 1974).

The present study extends the previous work by examining the spatial and temporal characteristics of selective attention when subjects must integrate information from different parts of the visual field before initiating a response. The temporal parameters of stimulus presentation were short enough to preclude facilitation from eye movements during the stimulus sequence. The necessity for processing information from more than one location after a single tachistoscopic exposure allows a finer grained analysis of the spatio-temporal nature of visual selective attention. Specifically, the subjects' task in the present experiment was to indicate by a lever movement whether two indicated letters in a tachistoscopically presented eight-letter display were the same or different. RT was the dependent variable, while physical separation, response type, and stimulus onset asynchrony (SOA) between indicators and letters were the independent variables.

If the iconic store functions like a computer's core memory with all stimulus elements analyzed in parallel and held briefly in a random access storage system, then the attentional mechanism should be able to access any pair of letters with equal ease and RT should not vary as a function of physical spacing or the number of intervening noise letters between the target letters of a pair.

A second possibility is that the attentional field consists of a single locus of high information extraction capacity which subtends a fixed size and shape and moves about the icon with limited speed much as the fovea moves about the visual field. Then, other things being equal, RT should increase with spatial separation of the target letters. 
A third possibility is that there is a movable focus of attention which requires only negligible transit time once the stimulus pattern has been structured preattentively. This model would not imply a monotonic relationship between spacing and RT but would allow for an effect of spacing due to the spatial characteristics of the gradient of information extraction at each fixation of this metaphorical "internal eyeball" (cf. Eriksen \& Hoffman, 1973; Eriksen \& Eriksen, 1974). Each such act of attention may result in the detailed processing of the indicated letter as well as some processing of the letters adjacent to the indicated letter. In addition, a movable focus of attention could conceivably pick up intervening letters as it scans from one indicated position to the other.

\section{METHOD}

\section{Subjects}

Six paid subjects from the University of Illinois, five of them female, served in two practice and six experimental sessions. Each was right-handed and had normal or corrected-to-normal vision. Three subjects moved the lever left for same and right for different, while the other three had the opposite response assignment.

\section{Apparatus and Procedure}

Stimuli were presented in a Scientific Prototype three-channel tachistoscope with Sylvania F4T5/CWX lamps. Viewing was binocular at $140 \mathrm{~cm}$. Luminance was held constant at $5 \mathrm{fL}$ throughout the experiment.

Thirty-two circular displays of eight black uppercase letters (24-pica point Futura Bold, Paratipe No. 11317) were constructed on white vinyl cards. Letters were $.22 \mathrm{deg}$ of visual angle high and appeared along the circumference of an imaginary circle 2 deg of visual angle in diam, in the $3,6,9$, and 12 o'clock positions and the four positions midway between these.

The Letters A, C, U, and $W$ appeared twice in each display in a random arrangement. Across the set of cards, each letter appeared equally often in each position. Two black bars, subtending $.5 \mathrm{deg}$ by $.13 \mathrm{deg}$, indicated the two target letters. The indicators appeared external to the circle of letters on imaginary radii, with their near ends $.5 \mathrm{deg}$ of visual angle from the centers of the indicated letters.

The order of same and different trials varied randomly within a block, with the correct response "same" as often as "different." Each letter was indicated equally often as a member of a same or a different pair, and a given pair was indicated equally often at each of the four separations.

A black fixation cross $.33 \mathrm{deg}$ of angle across appeared between trials and continued until the subject initiated a trial by pressing a button with the left hand. The subject was told to fixate on the cross and to try and avoid eye movements during trials.

When the subject initiated a trial, the fixation cross was immediately replaced by Field 2 of the tachistoscope, which was on for $80 \mathrm{msec}$. Field 2 contained two indicators in the leading indicators (80-SOA) condition, or a black dot subtending $.22 \mathrm{deg}$ of visual angle in the stimultaneous indicators (O-SOA) condition. The black dot was to control for nonpositional warning effects and to keep the interval from trial initiation to letter onset constant across indicator conditions.

Field 2 was followed by Field 3, which contained the letter display at a duration of $80 \mathrm{msec}$. In the O-SOA condition, Field 3 also contained the indicators on a clear vinyl card inserted in front of the letters. Extra clear vinyl cards were inserted where appropriate to keep luminance constant regardless of SOA condition. Two practice sessions allowed subjects to learn the required responses so as to reduce errors and $\mathrm{RT}$ variability.
Subjects received RT feedback after each practice trial and after each block of experimental trials. They were immediately informed of any errors. Two subjects were dropped for excessive error rates during the practice sessions.

There were four 32-trial blocks in each session, two at $80 \mathrm{msec}$ SOA and two at $0 \mathrm{msec}$ SOA. Two consecutive sessions constituted a replication, with each subject receiving the same 128-letter and indicator combinations at each SOA. The order of SOAs was counterbalanced across sessions and subjects in a modified Latin square.

Subjects were given warm-up trials at the start of each session and each block. They were told to make the lever response as fast as possible without making mistakes. Errors were rerun later in the session. As a check on guessing, subjects named the indicated letters, without time pressure, after making the lever response.

\section{RESULTS}

A repeated measures analysis of variance was done on mean correct RTs. All main effects were significant: SOA $[\mathrm{F}(1,5)=74.462, \mathrm{p}<.0004]$; response type $[F(1,5)=25.319, \quad \mathrm{p}<.004] ;$ and separation $[F(3,15)=25.931, p<.00001]$. The interaction of response type by separation was also significant $[F(3,15)=6.836, p<.004]$.

Mean correct RTs for all conditions are shown in Figure 1. RTs were faster by an average of $41 \mathrm{msec}$ when indicators preceded the letters than when they were simultaneous. Adjacent and diametrically opposite target pairs were fastest, with pairs at intermediate spacings somewhat slower. The slowest spacing overall was two positions removed, i.e., with one intervening letter. The interaction of response type by separation shows up as a greater RT advantage of same over different responses at the adjacent and diametrically opposite spacings than at the intermediate spacings.

Overall error rate was $5.7 \%$. Error percentages were generally similar to RT results. Subjects were

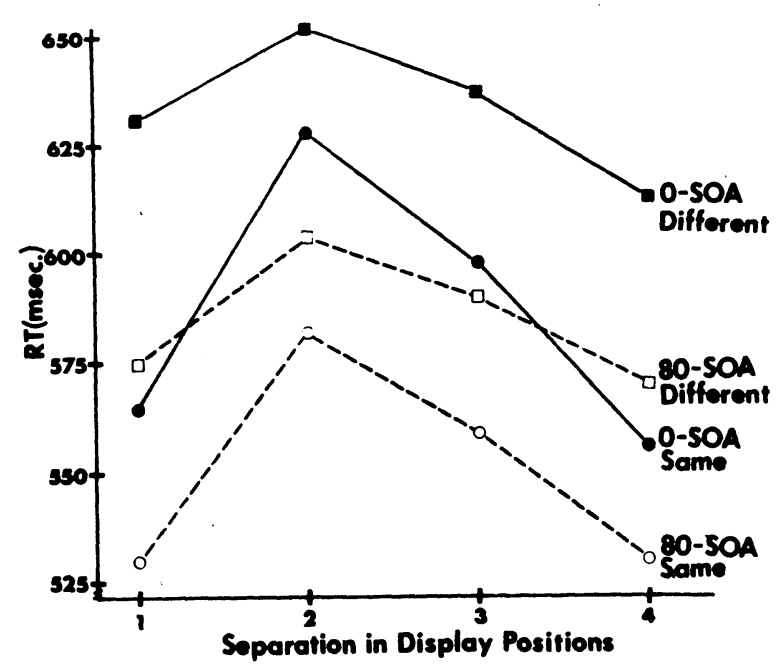

Figure 1. Mean correct reaction time (RT) as a function of spacing between indicated positions, type of response, and stimulus onset asynchrony (SOA) between indicators and letters. 


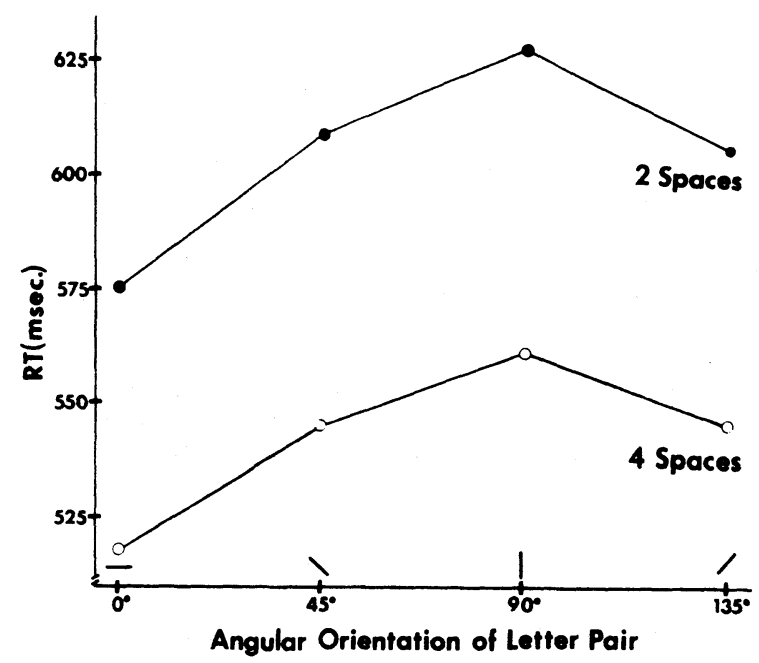

Figure 2. Mean correct $R T$ as a function of angular orientation of the two indicated positions for same pairs two and four spaces apart.

more likely to err by responding "different" when a same pair was indicated than the reverse, which indicates that the faster RT for same is not merely due to a greater readiness to make the "same" response. Most errors consisted of an incorrect lever movement followed by a correct identification. Subjects named the wrong letters only $1.0 \%$ of the time.

Letter pairs presented to one side of the fixation point are initially processed by the contralateral cerebral hemisphere. Letter pairs which appeared at smaller separations were more likely to go to the same hemisphere than widely separated pairs. Interhemispheric vs. intrahemispheric presentation thus covaried with spacing, with the diametrically opposite pairs having the greatest probability of interhemispheric presentation. The data were examined to see if a possible superiority of interhemispheric presentation or an effect of orientation per se could account for part of the spacing effect. Figure 2 shows RTs for correct same responses at two and at four spaces as a function of angular orientation, averaged across subjects and SOAs. These spacings provide the best test for hemispheric effects in the present experiment. There is a clear effect of spacing at each orientation, with the diametrically opposite pairs over $50 \mathrm{msec}$ faster than the two-space pairs, regardless of orientation. Angular orientation affected RT in a manner apparently independent of the spacing effect. Obliquely oriented pairs were slower than horizontal pairs, and vertical pairs were slowest of all, at both spacings. Adjacent same pairs were also reanalyzed and showed a similar trend across orientations. Spacing thus had an effect independent of hemispheric effects or orientation.

\section{DISCUSSION}

The faster RTs obtained with leading (80-SOA) as opposed to simultaneous indicators are in accord with previous results from this lab (Colegate, Hoffman, \& Eriksen, 1973; Eriksen \& Colegate, 1971) and may reflect advanced programming of the attentional mechanism. The fact that same responses were faster than different responses likewise replicates previous work involving letter pairs (Nickerson, 1965).

The principle concern in the present experiment was the effect of physical separation between target letters, when target letters at each spacing appeared on foveal locations of equal acuity and there was no possibility of facilitatory eye movements. The results with regard to spacing can discriminate between the three visual selective attention models presented in the introduction.

The existence of any main effect of spacing rules out the first model, which had stimulus elements being independently addressable like individual locations in a computer's core memory. In the second model, the time to compare target letters increased monotonically with distance between the indicated positions. The results clearly rule out this model. Time to shift attention between locations, or the resistance of the attentional field to being split into two segments cannot account for adjacent pairs and diametrically opposite pairs being faster than pairs at the intermediate spacings.

Only the third model is in accord with the data. In this model, there is an initial preattentional structuring of the visual display (cf. Hoffman, 1975), which can locate the indicators and tag the indicated positions for further processing. Once the display has undergone this preliminary analysis, or preattentive processing (Neisser, 1967), an attentional focus can be quickly brought to bear on the indicated positions, with a constant small transit time between positions. Any effect of spacing on RT would be due to the spatial gradient of information extraction at each indicated position, or to the picking up of noise while scanning between indicated positions.

\section{REFERENCES}

Colegate, R. L., Hoffman, J. E., \& Eriksen, C. W. Selective encoding from multielement visual displays. Perception \& Psychophysics, 1973, 14, 217-224.

Eriksen, C. W., \& Colegate, R. L. Selective attention and serial processing in briefly presented visual displays. Perception \& Psychophysics, 1971, 10, 321-326.

Eriksen, B. A., \& Eriksen, C. W. Effects of noise letters upon the identification of a target letter in a nonsearch task. Perception \& Psychophysics, 1974, 16, 143-149.

ERIKSEN, C. W., \& Hoffman, J. E. Some characteristics of selective attention in visual perception determined by vocal reaction time. Perception \& Psychophysics, 1972, 11, 169-171. (a)

ERIKsen, C. W., \& Hoffman, J. E. Temporal and spatial characteristics of selective encoding from visual displays. Perception \& Psychophysics, 1972, 12, 201-204. (b)

Eriksen, C. W., \& Hoffman, J. E. The extent of processing of noise elements during selective encoding from visual displays. Perception \& Psychophysics, 1973, 14, 155-160.

ERIKSEN, C. W., \& Rohrbaugh, J. W. Some factors affecting the efficiency of selective attention. American Journal of Psychology, 1970, 83, 330-342.

Geissler, L. R. A critique of Professor Wirth's methods of measurement of attention. American Journal of Psychology, $1909,20,120-130$.

HofFman, J. Hierarchical stages in the processing of visual information. Perception \& Psychophysics, 1975, 18, 348-354.

JAMES, W. The principles of psychology (Vol. 1). New York: Holt, 1890.

NeIsser, U. Cognitive Psychology. New York: Appleton-CenturyCrofts, 1967.

Nickerson, R. S. Response times for "same"."different" judgments. Perceptual and Motor Skills, 1965, 20, 15-18.

WUNDT, W. Zur Kritik tachistoscopischer Versuche. Philosophische Studien, 1900, 15, 287-317.

(Received for publication October 9, 1975.) 